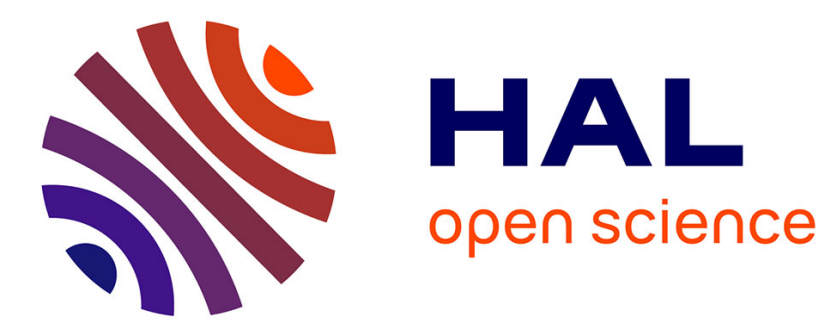

\title{
Thermodynamic Methods and Models to Study Flexible Metal-Organic Frameworks
}

\author{
François-Xavier Coudert, Anne Boutin, Marie Jeffroy, Caroline
}

Mellot-Draznieks, Alain H. Fuchs

\section{- To cite this version:}

François-Xavier Coudert, Anne Boutin, Marie Jeffroy, Caroline Mellot-Draznieks, Alain H. Fuchs. Thermodynamic Methods and Models to Study Flexible Metal-Organic Frameworks. ChemPhysChem, 2011, 12 (2), pp.247-258. 10.1002/cphc.201000590 . hal-02116872

\section{HAL Id: hal-02116872 \\ https://hal.science/hal-02116872}

Submitted on 1 May 2019

HAL is a multi-disciplinary open access archive for the deposit and dissemination of scientific research documents, whether they are published or not. The documents may come from teaching and research institutions in France or abroad, or from public or private research centers.
L'archive ouverte pluridisciplinaire HAL, est destinée au dépôt et à la diffusion de documents scientifiques de niveau recherche, publiés ou non, émanant des établissements d'enseignement et de recherche français ou étrangers, des laboratoires publics ou privés. 


\title{
Thermodynamic Methods and Models to Study Flexible Metal-Organic Frameworks
}

\author{
François-Xavier Coudert, ${ }^{[a]}$ Anne Boutin, ${ }^{[b]}$ Marie Jeffroy, ${ }^{[c]}$ \\ Caroline Mellot-Draznieks ${ }^{[\mathrm{d}]}$ and Alain $\mathrm{H}$. Fuchs ${ }^{*[a]}$
}

A lot of attention has recently been focused on a fascinating subclass of metal-organic frameworks that behave in a remarkable stimuliresponsive fashion. These soft porous crystals feature dynamic crystalline frameworks displaying reversible, large-amplitude structural deformations under external physical constraints such as temperature, electric field or gas exposure. The number of reported syntheses of such materials is rapidly growing and they are very promising for practical applications, such as gas capture, purification and fluid separation. Herein, we summarize the recently developed thermodynamic tools that can help understand the process of fluid

\section{Introduction}

Open framework nanoporous materials have been gaining increasing importance in industrial applications in the past decades. Zeolites are now widely used in industry as molecular sieves, ion exchangers and catalysts, to mention only a few of their most widespread applications. More recently, a lot of attention has focussed on porous hybrid organic-inorganic frameworks (or metal-organic frameworks, MOFs), a topical class of materials that display an extremely large range of crystal structures and tuneable host-guest properties..$^{1,2,3,4,5}$ Members of this family were demonstrated to be very promising for applications such as the capture of strategic gases, ${ }^{6,7,8,9,10,11}$ fluid separation, ${ }^{12}$ heterogeneous catalysis ${ }^{13}$ and drug delivery, ${ }^{14}$ as well as having potential use as sensors, actuators and nanomoulds. ${ }^{3}$

As any complex molecular structure, all nanoporous frameworks exhibit some degree of flexibility, depending on their chemical nature, structure and topology. Zeolites, being built with strong, rigid metal-oxygen bonds ( $\mathrm{Si}-\mathrm{O}$ bonds are among the strongest covalent bonds known), typically display limited structural flexibility. In that case, deformation is only triggered by adsorption at high pressures ${ }^{15,16}$ or by high temperatures, ${ }^{17}$ and it induces limited changes in lattice parameters and pore diameters. However, even this limited flexibility is known to have consequences on the properties of some materials, such as negative thermal expansion, ${ }^{18,19,20}$ and on the physicochemical properties of confined fluids in these materials. This is particularly the case for diffusion and transport properties, ${ }^{21,22,23}$ as well as vibrational properties, ${ }^{24}$ which are very sensitive to the flexibility of the host framework. The effect of this limited flexibility is smaller on the thermodynamics of adsorption of guest molecules, though it can lead to some cases of accommodation of larger molecules than geometrically possible according to the empty host adsorption and fluid mixture coadsorption in these flexible nanoporous materials. These tools, which include both molecular simulation methods and analytical models, can help rationalize experimental results and predict adsorption properties over a wide range of thermodynamic conditions. A particular focus is given on how these methods can guide the experimental exploration of a large number of materials and working conditions (temperature, pressure, composition) to help design efficient processes relying on fluid adsorption in soft porous crystals.

structures, or even to phase transitions of the zeolite upon guest adsorption. One of the few examples of zeolites where flexibility has a known influence on adsorption is silicalite-1. This material was shown to possess three different crystalline structures,$^{25}$ with close unit cell volume ( 0.6\% difference), between which adsorption-induced transitions were observed. ${ }^{25,26}$ Other known flexible zeolites display this flexibility in other ways, including reversible shrinking of the framework upon solvent removal (e.g. for zeolite Na-MAP ${ }^{27}$ and germanate ASU- $16^{28}$ ), temperaturetriggered phase transitions (e.g. in zeolite $\mathrm{Sr}-\mathrm{RHO}^{29}$ ) as well as framework displacement upon cation exchange (as in zeolites $\mathrm{Ca}, \mathrm{H}-\mathrm{RHO}, \mathrm{Sr}-\mathrm{RHO}, \mathrm{Ba}-\mathrm{RHO}, \mathrm{Cd}-\mathrm{RHO}$ and $\mathrm{Na}, \mathrm{Cs}-\mathrm{RHO}^{30}$ ).

By contrast with zeolites, metal-organic framework materials involve significantly weaker bonds (coordinative bonds, $\pi-\pi$ stacking, hydrogen bonds, etc.) that are responsible for their intrinsic structural flexibility. Unlike in purely inorganic frameworks the organic-inorganic connections therefore allow underconstrained structural linkages that are responsible for mechanical properties fundamentally different from those of inorganic crystalline materials. Under stimulus, structural transformations may therefore be induced, involving low energy interactions or distortions such as bond bending or torsion rather than strong individual covalent or iono-covalent bonds. It is typical that the existence of unprecedented negative thermal expansion properties have been reported in a number of families of metal-

\footnotetext{
[a] Dr. François-Xavier Coudert, Prof. Dr. Alain H. Fuchs Chimie ParisTech \& CNRS

11 rue Pierre et Marie Curie, F-75005 Paris, France E-mail: alain.fuchs@cnrs-dir.fr

[b] Dr. Anne Boutin

Chemistry Department, École Normale Supérieure, CNRS \& UPMC 24 rue Lhomond, F-75005 Paris, France

[c] Dr. Marie Jeffroy

Laboratoire de Chimie Physique, Université Paris-Sud 11 \& CNRS Bât. 349, F-91405 Orsay, France

[d] Dr. Caroline Mellot-Draznieks

Chemistry Department, University College London

20 Gordon Street, WC1H OAJ, United Kingdom
} 


\begin{tabular}{|c|c|c|c|c|c|c|}
\hline Family & Material & Composition & Structure & Phenomenon displayed & $\begin{array}{l}\text { Cell volume } \\
\text { variation }^{[a]}\end{array}$ & Ref. \\
\hline \multirow[t]{4}{*}{ zeolites } & SSZ-73 & $\mathrm{SiO}_{2}$ & $\begin{array}{l}\text { SAS framework type, } \\
\text { 1D channels }\end{array}$ & $\begin{array}{l}\text { Framework dynamics, which } \\
\text { impacts guest diffusion }\end{array}$ & $\sim 0$ & 23 \\
\hline & $\mathrm{AlPO}_{4}-17$ & $\mathrm{AlPO}_{4}$ & ERI framework type & Negative thermal expansion & $0.2 \%$ & 20 \\
\hline & Silicalite-1 & $\mathrm{SiO}_{2}$ & MFI framework type & Multistability ( 3 phases) & $0.6 \%$ & 25 \\
\hline & Na-MAP & $\mathrm{NaSiAlO}_{4}$ & GIS framework type & Contraction upon dehydration & $20 \%$ & 27 \\
\hline \multirow[t]{6}{*}{ MOFs } & ZIF-8 & $\mathrm{Zn}$ (methyimidazolate $)_{2}$ & $\begin{array}{l}\text { 3D-connected cavities, } \\
\text { LTA framework type }\end{array}$ & $\begin{array}{l}\text { Intra-framework dynamics } \\
\text { (imidazolate rotation) }\end{array}$ & $\sim 0$ & 50 \\
\hline & IRMOF-1 & $\left(\mathrm{Zn}_{4} \mathrm{O}\right)(1,3-\mathrm{bdc})_{3}$ & 3D-connected cavities & Negative thermal expansion & $0.8 \%$ & 31 \\
\hline & MIL-88C & $\mathrm{Cr}_{3} \mathrm{O}\left(\mathrm{H}_{2} \mathrm{O}\right)_{2} \mathrm{~F}(2,6-\mathrm{ndc})$ & 3D-connected channels & Swelling with pyridine & $270 \%$ & 39 \\
\hline & $\mathrm{Cu}(4,4$ '-bipy & 5-dihydroxybenzoate) 2 & Stacked layers & Gate opening & Unknown & 44 \\
\hline & MIL-53 (Al) & $\mathrm{Al}(\mathrm{OH})(1,3-\mathrm{bdc})$ & Parallel 1D channels & Breathing & $40 \%$ & 41 \\
\hline & $\begin{array}{l}\mathrm{Cd}_{2}(\mathrm{pzdc})_{2} \mathrm{~L} \\
\text { hydroxyetho }\end{array}$ & $\begin{array}{l}=2,5 \text {-bis }(2- \\
\text { is }(4 \text {-pyridyl)benzene }\end{array}$ & $\begin{array}{l}\text { Pillared layered, } \\
\text { with rotatable pillar }\end{array}$ & Multistability (many structures) & Up to $38 \%$ & 45 \\
\hline
\end{tabular}

organic frameworks such as IRMOFs ${ }^{31}$ and metallocyanides. ${ }^{32}$ In addition to local, thermal relaxation of the porous framework, one fascinating aspect of MOFs is the ability of a subclass of structures to behave in a remarkable guest-responsive fashion. ${ }^{33,34,35,36}$ These so-called Soft Porous Crystals (SPC) $)^{37}$ exhibit a variety of large amplitude dynamic behaviour of their frameworks in response to external stimuli of weak intensity (light, electric field, gas exposure...). The change in the SPC channels in response to the external constraint is reversible and maintains the crystalline character of the solid in most cases. For some materials, the deformation is a continuous process, such as a swelling of the material upon gradual guest insertion. The MIL-88 family, for example, exhibits a massive swelling of the materials upon solvent adsorption (up to $270 \%$ in unit cell volume), enabled by an internal degree of freedom of the organic linker, namely the rotational freedom of the carboxylic group of this dicarboxylic acid relative to the central aromatic ring. ${ }^{38,39}$ This dynamics of the organic linker, while it is not a sufficient condition in itself for overall structural changes (as exemplified below on the ZIF family), is a distinctive property that differentiates flexible frameworks from isostructural materials with a rigid framework. ${ }^{40}$ Other materials exhibit bi- or multi-stability, i.e. the existence of two or more metastable framework structures whose relative stability is influenced by a physicochemical stimulus. The MIL-53 family of highly flexible, bistable porous hybrid materials ${ }^{41,42,43}$ feature in this category, along with materials exhibiting "gate opening", ${ }^{44,44,45,46,47}$ i.e. the adsorption-induced transition from a nonporous to a microporous structure. Finally, some of these materials with dynamic frameworks include limited capacity for overall unit cell expansion or contraction, but possess internal degrees of freedom of their linkers. The most impressive examples of this last category are Zeolitic Imidazolate Frameworks. ${ }^{48,49,50,51,52}$ The ZIFs, a subclass of MOFs, have frameworks that closely resembles that of zeolites, with a metalimidazolate-metal angle of $145^{\circ}$ replacing the zeolites' Si-O-Si angle of the same value. The strong constraint on the porous framework imposed by the fixed value of this angle severely limits the flexibility of the ZIFs, as is the case for zeolites, implying a similar lattice energy/density trend than in zeolites. ${ }^{53}$ However, the dynamic nature of ZIFs is displayed by the large-amplitude motions of the imidazolate linkers that can rotate (at fixed metalimidazolate-metal angle).

An important, and still rapidly growing, number of these soft porous crystals were reported in the literature; for recent reviews, see Refs. 5, 36 and 37 . The list of possible stimuli inducing the flexibility or the crystal-to-crystal transformation includes: temperature, ${ }^{54}$ mechanical pressure, ${ }^{55}$ light, ${ }^{56}$ electric field, magnetic fields, gas and liquid sorption. For the specific, widely studied case of adsorption-induced structural deformation (or "breathing"), work has been done to relate the chemical, structural and topological properties of the materials with the existence or absence of breathing. ${ }^{5,35}$ In particular, Kitagawa proposed to classify the flexible MOFs into six classes, according to the dimensionality of the material's framework and that of its organic and inorganic subnetworks. ${ }^{36}$ It is also noteworthy that a recent study has demonstrated the possibility to tune the flexibility of a given material by postsynthetic functionalization, opening the way to nanoporous solids with tailored dynamic behaviour. ${ }^{57}$

With the growing number of synthesised soft porous crystals and the large number of published studies of their physicochemical properties, many potential industrial applications have been envisioned for these materials, although none of them have yet reached the point of being used in the field. ${ }^{58}$ In addition to the applications of MOFs in general, specific applications of soft porous crystals aspire to exploit the large amplitude of the structural changes. For example, materials of the MIL-53 family ${ }^{41,42}$ feature an abrupt pore-shrinking structural transition in presence of a very low vapour pressure of various organic molecules and water, with guest-dependent transition pressure. These extreme sensitivity and selective breathing lead to propose these materials as sensors for detecting traces of organic molecules. ${ }^{5}$ Moreover, materials of this same family also have potential applications in gas separation at higher pressure, as was demonstrated in the case of the $\mathrm{CO}_{2} / \mathrm{CH}_{4}$ mixture, ${ }^{59,60}$ and 

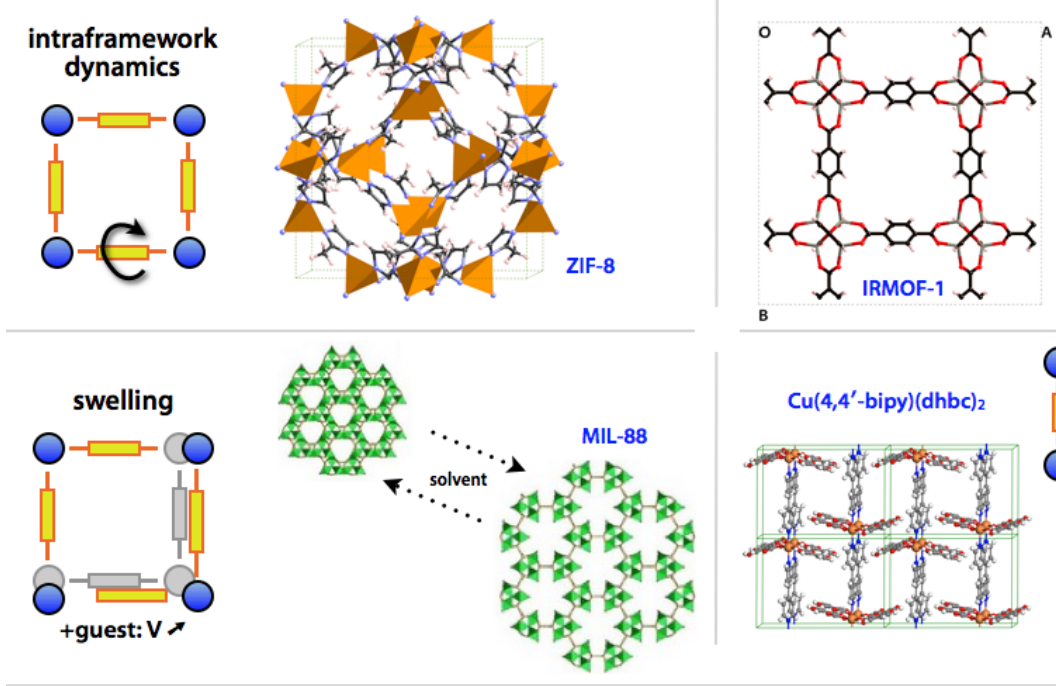

negative thermal expansion

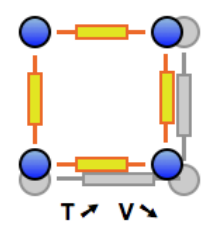

B
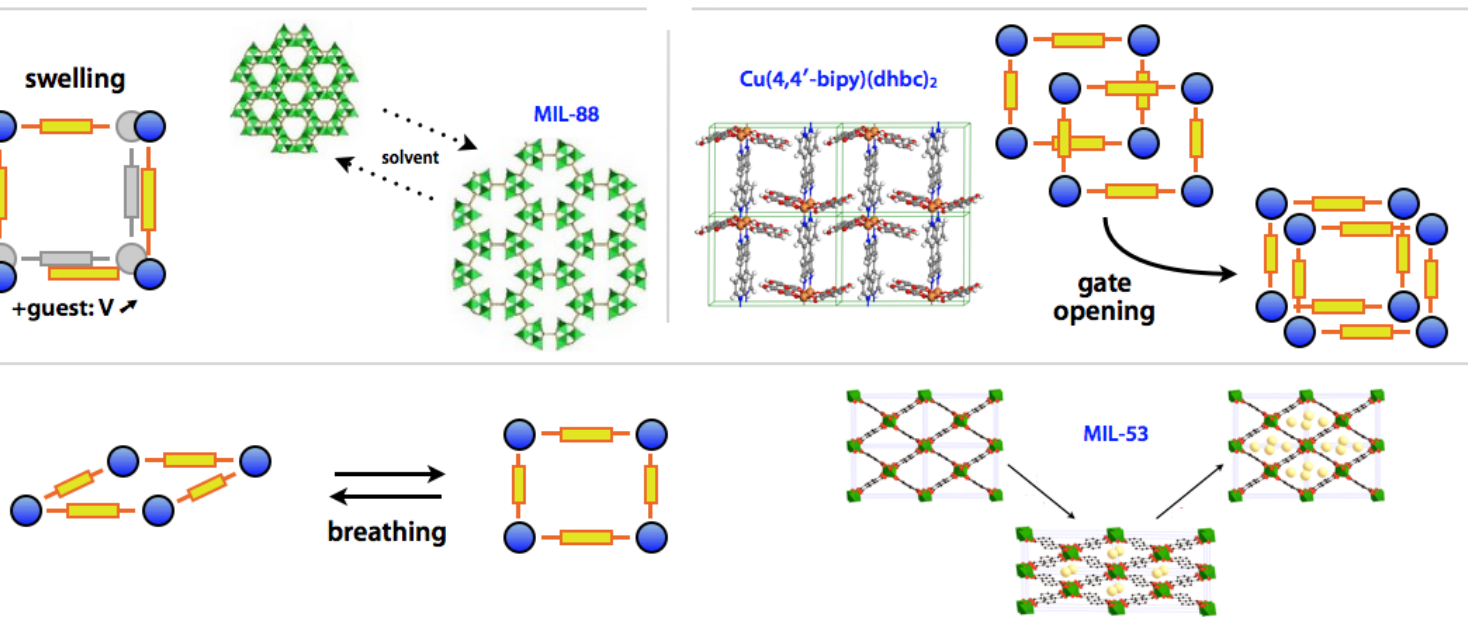

Figure 1. Different categories of dynamic metal-organic frameworks, each illustrated by a material displaying the phenomenon.

this potential is directly linked to the bistability of the framework. ${ }^{61,62}$ Indeed, at room temperature, while the most stable structure for the empty material exhibits limited selectivity, adsorption of the mixture can trigger a transition to a form with narrower pores, which presents a much higher selectivity for $\mathrm{CO}_{2}{ }^{60}$ The same trend was further demonstrated by direct breakthrough experiments in the amino-substituted derivative $\mathrm{NH}_{2}$-MIL53, with an even larger selectivity. ${ }^{63}$ This selectivity is indeed expected to be systematically enhanced by the functionalisation of MIL-53 with a range of polar ligands. ${ }^{64,65}$ Moreover, gate-opening materials, with their wide hysteresis loop in the adsorption-desorption isotherms and the absence of porosity in their closed structure, are cited as prospective materials for storing fluids at high pressure, keeping them adsorbed at much lower pressure (thus presenting higher safety), and releasing them completely at low pressure (i.e. complete recovery) Finally, in addition to these adsorption and separation properties, soft porous crystals were investigated for use in drug delivery. Recent work indicates that, compared to rigid frameworks, some soft materials possess a slower release, with a kinetic close to zero-order. ${ }^{66}$ This distinct feature, desirable for long-release, unique-injection therapies, has been attributed to the flexibility of the framework providing an optimal host for the adsorbed molecule, whose unbinding is thus slowed.

As described above, adsorptive gas capture and separation feature prominently among the possible applications of soft porous crystals. It thus makes sense to understand the theoretical tools, models and concepts used today in this area, which has concentrated a large research effort in the last decades. Current industrial processes in these key areas typically use adsorbents such as zeolites, other zeolitic materials and activated carbons. Their technical design, as that of any adsorption process, relies on information about the adsorption equilibria of multicomponent systems in a large number of different thermodynamic conditions. Experimental determination of this information is expensive and time-consuming, considering the very large dimensionality of the parameter space for the problem. This has lead to the development and extensive use of many theoretical methods addressing these issues. For example, the industrial success of adsorptive separation processes, which rely on finding optimal conditions for gas separation in a given adsorbent, is linked to a great extent to the existence of a host of methods that predict multicomponent equilibrium properties based on pure component adsorption data. The simplest of these methods is the Ideal Adsorbed Solution Theory (IAST), ${ }^{67}$ but many more elaborate methods are used to take into account the nonideality of fluid mixtures. ${ }^{68}$ On another level, molecular simulation of adsorption in rigid nanoporous materials is now part of the standard toolbox in the field and is routinely used to understand and predict the properties of known materials in untested conditions. It also brings a better understanding of the relation between microscopic and macroscopic properties of molecular fluids confined in nanopores and helps design better adsorbents and molecular sieves.

However, theoretical tools developed to study the thermodynamics of fluid adsorption in nanoporous materials most often consider the host matrix as a completely rigid framework. This is quite different from other properties of adsorbed fluids, such as structure, ${ }^{69,70}$ dynamics, ${ }^{24}$ transport $^{21,22,23,69,71,72,73}$ and electronic properties, ${ }^{74}$ which have all been studied in flexible frameworks by means of molecular dynamics methods, and for which the impact of host flexibility has been characterized. Only recently has some work been done to understand the thermodynamics of adsorption-induced structure changes (adsorption deformation) and account for it in molecular simulation methods ${ }^{61,62,75}$ and analytical models. ${ }^{76}$ Still, these studies mainly concern local or continuous deformation of the materials (swelling), and little has been done to understand the thermodynamics at play in a complete \{host, guest\} system where structural transitions may be induced by adsorption. For example, the well-known coadsorption models (such as IAST) are not applicable to these materials, as they fail to take into account the guest-induced changes in the structure upon adsorption. Moreover, there is a severe dearth of experimental data on gas 
coadsorption in flexible MOFs, ${ }^{59,60,63}$ compared to the published data available for pure component adsorption. There is thus a need for theoretical models to rationalize and predict the structural transitions and adsorption properties of pure components and mixtures in soft porous crystals, over a wide range of thermodynamic conditions (temperature, pressure, mixture composition, ...). It is only recently that a frame for the thermodynamics of flexible nanoporous solids, including metalorganic frameworks, has been proposed, ${ }^{25,76}$ allowing a tentative rationalization of guest-induced structural transitions.

This minireview presents recent advances in the general understanding of flexible porous materials, ranging from zeolites to metal-organic frameworks, including the development of theoretical thermodynamic tools based on the osmotic ensemble to study the adsorption of fluids and fluid mixtures in flexible nanoporous materials. After a brief presentation of the osmotic ensemble and an overview of the possibilities and difficulties of direct molecular simulation, we will introduce the sub-osmotic ensemble. We will then highlight a series of recent analytical methods developed to rationalize and predict the behaviour of soft porous crystals in wide ranges of thermodynamic conditions (temperature, pressure, and mixture composition). We will conclude by presenting an outlook for these methods.

\section{The Osmotic Ensemble}

\subsection{Statistical thermodynamics definition}

We consider here the general process of adsorption of a fluid in a nanoporous material, where the host framework undergoes structural deformations and/or host phase transitions induced by the adsorption of the fluid. This process is most appropriately described in the osmotic thermodynamic ensemble $\left(N_{\text {host }}, \mu_{\text {ads }}, \sigma, T\right),{ }^{25,77,78,79,80,81,82}$ where the control parameters are the number of molecules of the host framework $N_{\text {host }}$, the chemical potential of the adsorbed fluid $\mu_{\text {ads, }}$ the mechanical constraint $\sigma$ exerted on the system (which, in an isotropic system, is simply the external pressure $P$ ) and the temperature $T$. It differs from the isothermal-isobaric $(N, P, T)$ ensemble in that it is an open system for some of its components, whose chemical potential is imposed, representing thermodynamic equilibrium with an external reservoir. It is also different from the grand canonical ensemble $(\mu, V, T)$ as the volume is not conserved, but the pressure is imposed. For these reasons, the osmotic ensemble is sometimes referred to as a "semi-grand ensemble", though the scope of this term is not well established and also covers ensembles in which the total number of molecules is fixed but the composition can vary: $\left(N_{1}+N_{2}, \mu_{1}-\mu_{2}, V, T\right)$ ensembles. Finally, it is also worth noting that both the semi-grand and osmotic ensembles have at times been called " $(\mu, P, T)$ ensembles". This notation is improper, because such an ensemble would have only intensive control variables and the extensive conjugate variables would thus be unbounded. The osmotic ensemble, on the other hand, is a well-defined ensemble as long as the extensive control variable $\left(N_{\text {host }}\right)$ imposes an upper bound on the volume $V$ of the system, as is the case here for a solid that has a finite extensibility.

The thermodynamic potential $\Omega_{\mathrm{os}}$ and configuration integral $Z_{\text {os }}$ in the osmotic ensemble are given by the following equations: ${ }^{83}$

$$
\begin{aligned}
& \left.Z_{\mathrm{os}}=\sum \sum \sum \exp -\beta U(\mathrm{q})+\beta\left(\Sigma \mu_{i} N_{i}\right)-\beta P V\right) \\
& \Omega_{\mathrm{os}}\left(T, P, \mu_{i}, N_{j}\right)=-k T \ln \left(Z_{\mathrm{os}}\right)=U-T S-\sum \mu_{i} N_{i}+P V
\end{aligned}
$$

where index $i$ runs over the adsorbed species (whose chemical potential is imposed) and index $j$ runs over the host species (whose quantity is fixed).

\subsection{Molecular simulation in the osmotic ensemble}

Before embarking into the description of how molecular simulation of adsorption phenomena can be performed in the osmotic ensemble, we propose here a brief overview of the other systems that can be studied with it. The osmotic ensemble was first proposed (and implemented) by Mehta and Kofke ${ }^{77}$ in 1994 for the simulation of coexistence phase diagrams of liquid mixtures. In this early work, it was presented together with the semi-grand ensemble, and the results and convergence properties of both approaches were compared. Both approaches were later theorized by Escobedo, and formulated as instances of the more general concept of pseudoensembles. ${ }^{84}$ They were chiefly used to predict multicomponent phase equilibria in dense systems, working around the convergence issues of standard techniques (Grand Canonical or Gibbs ensemble simulations) for dense fluids. The term of "pseudoensemble", by contrast with regular ensembles, comes from the limitation that for mixtures of simple molecular species, the $\left(N_{1}, \mu_{2}, P, T\right)$ ensemble is not actually well-defined as the volume is not bounded $\left(N_{2}\right.$ and $V$ can grow together to infinity). In this formulation, the use of the osmotic ensemble can be seen as a methodological trick for accelerating convergence, by sampling phase space in a region larger than (but close to) the standard ensembles, rather than a full-bodied statistical mechanics ensemble.

Starting in 1996 with Theodorou et al, a number of research groups proposed various closely-related Monte Carlo simulation schemes based on the use of the osmotic ensemble, ${ }^{78,79,80}$ mainly in the domain of gas solubility in polymers. This particular research area is a good fit with the osmotic ensemble, as it is both necessary and well-defined for this problem. Firstly, it is necessary, because swelling of the polymer network accounts for a large share of the solubility of gases in polymer melts, which Grand Canonical simulations would not take into account. Secondly, it is well-defined because the polymer chains in a melt are strongly interlaced and entangled, giving the system a finite extensibility in the part of phase space that will be sampled. As a consequence, Monte Carlo simulation techniques based on the osmotic ensemble are widely used in the domain of phase mixtures containing long chain molecules.

\subsection{The case of adsorption in nanoporous materials}

A second (and more recent) area where the use of the osmotic ensemble is of great benefit is that of adsorption in porous solids. There is ample literature on the topic of fluid adsorption in zeolites and on the application of both theoretical models and molecular simulation techniques to understand the adsorption process at the molecular level. In particular, Grand Canonical Monte Carlo simulation methods, taking place in the eponymous statistical ensemble, are now very widely used and part of the standard molecular simulation toolbox for calculating thermodynamic adsorption properties in rigid materials. New Monte Carlo algorithms allow the simulation of systems that were considered 
impossible to study via computer simulations a few years ago (for instance long alkane chains, ${ }^{85}$ halocarbon or aromatic molecules $^{86,87}$ and water ${ }^{88,89}$ ). In most of these studies, a rigid framework is assumed for the adsorbent. This approximation is indeed quite decent for a large number of nanoporous solids (zeolitic materials in particular), for which framework flexibility is assumed to play a role in transport properties, ${ }^{21,22}$ but not much on thermodynamics. Its immense advantage is that such simulations only require the description of the host-guest and guest-guest interactions, and there is no need for a forcefield parameterisation for the dynamics of the porous material itself (in contrast with other methods, as we will see later).

In order to perform a molecular simulation of adsorption in a flexible porous solid, there are two main approaches. The first one considers that, while the adsorption of fluid may influence the structure of the host framework, the deformation of the solid will be local and, in a reasonable range of temperature and pressure, the overall contraction or swelling of the solid is negligible. Such simulations keep the solid unit cell parameters fixed while allowing the individual atoms of the solid to move. They still take place in the Grand Canonical ensemble. This approximation is particularly suited to describe fluid adsorption in materials whose organic linkers may rotate without affecting the solid overall (e.g., ZIFs), or in dynamic interpenetrated frameworks, where two or more sublattices move with respect to one another. Many examples of this behaviour are found in the recent literature, ${ }^{44,90,91}$ and theoretical efforts to understand these phenomena have been done using "jungle-gym" structures as an ideal representation of a two-fold interpenetrated framework. ${ }^{92}$ The fixed unit cell approximation has also been used to study the influence of local framework dynamics, for example, on studies of noble gas adsorption in IRMOF-1, ${ }^{93}$ where flexibility was in the end demonstrated to have a negligible effect on sorption properties.

The second approach, which we will now discuss, fully accounts for the deformability of the host by performing molecular simulations in the osmotic ensemble, allowing the unit cell parameters of the solid to vary along the simulation, under a given external mechanical constraint (the pressure). The typical Monte Carlo moves considered during such a simulation are thus (schematized in Fig. 2):

- molecular moves of the adsorbate (translation, rotation, internal conformation changes, etc.),

- conformation changes of the host framework,

- molecule insertions and deletions, and

- changes of unit cell parameters.

The nature of the ensemble and the Monte Carlo moves involved induces very stringent requirements on the simulation. The first one is that a classical atomistic forcefield describing the fully flexible solid is required, in order to evaluate the energy of each sampled configuration of the framework. Due to the nature of the interactions that need to be reproduced (both bonding and nonbonding), and to the possibly complex molecular structure of the building blocks of the solid, optimization of such forcefields is a complex and time-consuming task. It typically involves making choices for the functional form of the potential components, guided by chemical knowledge of the system, and fitting the large number of parameters involved to a sufficient number of target properties gathered from experiments and quantum chemistry calculations. This was done in a number of flexible solids whose motions are limited to vibrations around an equilibrium configuration, where the intramolecular potential terms can be linked to vibration frequencies and thus chosen in a reasonably easy way. ${ }^{94,95}$ However, for nanoporous solids that display a large-amplitude swelling, and for bistable materials such as the breathing and gate-opening MOFs that can oscillate between two metastable framework structures, both the functional form of the potential and the optimization procedures are considerably less straightforward. Studies thus often resort to combining existing forcefields (e.g., CVFF or UFF for organic molecules) and adjusting them on a few selected properties (e.g. the energy difference between the metastable structures), ${ }^{61,62,} 96$ As a consequence, these ad hoc forcefields may or may not reproduce the physicochemical properties of the material in configurations widely different from the stable states (for example, the transition state of the structural transformation). Thus, the development of forcefields for soft porous crystals is a hot and topical challenge to the molecular simulation community, which currently limits the extent of direct simulations.

Another source of difficulty in osmotic ensemble molecular simulations is the acceptance ratio of unit cell changes. The issue comes from the fact that in a volume change move, the adsorbed species need to be displaced as well as the unit cell; typically, the unit cell is rescaled by keeping the sorbates' reduced coordinates fixed. This move involving a large number of molecules in a condensed state is often energetically unfavourable, and volume changes thus have a low acceptance probability that hinders the sampling of configuration space. To work around this issue, Monte Carlo simulations in the osmotic ensemble are typically performed following a Hybrid Monte Carlo (HMC) scheme, where short molecular dynamics simulations in the $(N, P, T)$ ensemble are considered as single Monte Carlo steps. ${ }^{97,98,99}$ The intrinsically collective nature of the motions during the molecular dynamics provides volume changes with a higher acceptance probability, and thus a more efficient convergence towards thermodynamic equilibrium. One issue this does not solve, however, is the severe convergence difficulties encountered when the porous solid can oscillate between several metastable structures, being bistable like the MIL-53 family, or oscillating between three close structures like silicalite-1. In this instance, more than in the case of swelling, the barriers present along the free energy landscape are hard to go over in a finite simulation time. This was observed, for example, in a very recent $\mathrm{HMC}$ simulation of $\mathrm{CO}_{2}$ adsorption in MIL-53 (Al), where it was evidenced that, in the simulation time allowed by modern computer hardware, only one of the two breathing transitions of the host material is ever observed, even though the total size of the system is relatively modest by today's standards. ${ }^{100}$

\subsection{The restricted osmotic ensemble}

As a consequence of the issues outlined above, very few atomistic molecular simulations in the osmotic ensemble were reported in the literature. Moreover, most of the studies published concern the phenomenon of adsorption-induced swelling rather than first-order structural transitions and multistable materials. In order to gain thermodynamic insight into the adsorption of fluid inside multistable materials, Jeffroy et al proposed a simulation scheme deriving from the osmotic ensemble in which the number of degrees of freedom of the host material is limited to a set of rigid structures. ${ }^{25}$ Thus, the porous solids is only allowed to assume a fixed number of conformations, corresponding to the metastable structures of its framework, rather than sampling its entire configuration space. As a consequence, the expression of the partition function is reduced to: 


$$
\begin{aligned}
Z_{\mathrm{os}}\left(\mu_{i}, N_{j}, P, T\right) & =\sum_{V} \sum_{N_{i}} \sum_{\mathrm{q}} \exp \left(-\beta U(\mathrm{q})+\beta\left(\Sigma \mu_{i} N_{i}\right)-\beta P V\right) \\
& \left.\left.\approx \sum_{V \in\left\{V_{k}\right\}} \exp -\beta P V\right)\left[\sum_{N_{i}} \sum_{\mathrm{q}} \exp -\beta U(\mathrm{q})+\beta\left(\Sigma \mu_{i} N_{i}\right)\right)\right] \\
& \left.=\sum_{V \in\left\{V_{k}\right\}} \exp -\beta P V\right) \times Z_{\mathrm{GC}}\left(\mu_{i}, V, T\right)
\end{aligned}
$$

where $Z_{\mathrm{Gc}}\left(\mu_{i}, V, T\right)$ is the grand canonical configuration integral for a given host structure with volume $V$. In essence, it reduces the sampling of phase space to a subset of the osmotic ensemble, and was hence termed the "osmotic sub-ensemble" or "restricted osmotic ensemble".

Based on this approximation, two possible simulation schemes were presented and compared by the authors. The first one is a direct approach, directly simulating structural changes during the simulation run but restricting the possible host structures to the predefined finite subset. This is made possible by replacing the "volume change" move of the osmotic Monte Carlo by a swap to a randomly chosen framework structure, at fixed relative positions of the guest molecules. The new "structure jump" move is thus a discrete counterpart of the "volume change" move (see Fig. 3). Observables can then be obtained as averages over the course of the simulation. In particular, one can calculate the equilibrium composition of the various host structures depending on adsorbate vapour pressure. This approach was tested on adsorption of $\mathrm{C}_{2} \mathrm{Cl}_{4}$ in silicalite-1, a zeolite with three different crystalline structures (ORTHO, MONO and PARA). ${ }^{25}$ There, it was demonstrated to reproduce the experimental stepped isotherm and confirmed that this step can be attributed to a MONO $\rightarrow$ PARA structural transition upon adsorption of tetrachloroethene. It also hinted that the ORTHO structure is present in significant proportion at intermediate pressures (up to $30 \%$ ), even though it is never the dominant component of the silicalite-1 phase mixture (see Fig. 4).

While the direct simulation approach to the restricted osmotic ensemble can be successful on a system such as silicalite-1, where the metastable crystalline phases are structurally close to one another (less than one percent difference in cell volume), it is negatively impacted by the issue of small acceptance probability for structure jumps in systems that exhibit large structural deviations. To remediate this, a second approach was proposed by Jeffroy et al, based on the last equality in Eq. $3 .^{25}$ This alternative consists of calculating the fluid adsorption isotherms in the different rigid host structures, in the Grand Canonical ensemble, and to calculate afterwards the corresponding osmotic grand potential. This allows the determination of the relative stability of each structure at any vapour pressure. In this scheme, separate simulations for each structure of the porous solid allow the calculation of so-called "rigid host" isotherms, $N_{k}(P)$ (where index $k$ runs over all metastable host structures). Once these isotherms are known, the corresponding Grand Canonical potential profiles are calculated from its derivatives, following Peterson and Gubbins: ${ }^{101,102}$

$$
\Omega_{\mathrm{GC}}^{k}\left(\mu, V_{k}, T\right)=-\int_{-\infty}^{\mu} N_{k}(\mu) \mathrm{d} u
$$

and the osmotic grand potential for each phase $k$ can be calculated as:

$$
\Omega_{\mathrm{nc}}^{k}(\mu, P, T)=\Omega_{\mathrm{nc}}^{k}\left(\mu, V_{k}, T\right)+P V_{k}+F_{\mathrm{hnc}}^{k}
$$

As a consequence, if the relative free energies of the host structures, $\Delta F_{\text {host, }}$ are known, their relative stabilities at each vapour pressure can be determined. This more indirect approach has the advantage of being just as simple as a series of GCMC simulations, while the effect of structural transitions and flexibility is accounted for a posteriori. The only requirement added to the GCMC simulations is an estimate of the relative energies of host structures. These latter can be determined experimentally (e.g. by calorimetry), by quantum chemistry calculations, or indirectly from experimental adsorption isotherms, as will be described in the next section. This method, demonstrated on $\mathrm{C}_{2} \mathrm{Cl}_{4}$ and $\mathrm{C}_{2} \mathrm{Cl}_{3} \mathrm{H}$ adsorption in silicalite-1, was shown to yield results similar to the direct approach and in good agreement with the experimental data available. ${ }^{25,103}$

\section{Analytical methods based on the osmotic ensemble}

From the review of the previous section, it clearly appears that the molecular simulation tools for the study adsorption in highly flexible materials, including in particular those possessing multistable frameworks, are very challenging to implement and use in real-life scenarios where adsorption strain can be large. In addition, there is also a lack of theoretical methods and models to help understand experimental results. The recent rapid growth of literature on adsorption properties of soft porous crystals has demonstrated the wide variety of behaviours they can exhibit. In order to rationalize these behaviours, a classification was proposed relying on framework topology ${ }^{35}$ and arguments were presented to link the presence or absence of flexibility to the solid's topology and connectivity. ${ }^{5}$ Most theoretical studies have been focussing exclusively on structural features, and the link between flexibility and guest adsorption has been approached from energetic considerations in selected structures, ${ }^{61,62,75}$ rather than taking into account the full thermodynamic picture. We offer here a short review and some perspectives of a series of theoretical methods recently proposed to help develop the understanding of adsorption thermodynamics in soft porous crystals. These methods rely on the thermodynamic equations of the osmotic ensemble. Their goal is to give insight into the behaviour of these systems as well as help interpret, postprocess and predict experimental adsorption results.

\subsection{A general model and taxonomy for adsorption-induced structural transitions}

The methods reviewed herein derive from the general thermodynamic framework laid out in Ref. 76, based on the analysis of experimental adsorption isotherms. These adsorption (and desorption) isotherms are the most easily accessible experimental observables in adsorption thermodynamics, as evidenced by the fact that they are routinely reported in the characterization of novel porous materials, in particular those suspected of possible applications in gas separation. In the case of gas adsorption in soft porous crystals, a substantial number of experimental adsorption data exhibit S-shaped or stepwise adsorption isotherms, frequently assorted with hysteresis loops, and linked to a structural transition from one host phase to another (pore opening or closing) upon adsorption. ${ }^{104}$ To help shed light into these guest-induced structural transitions, we proposed to apply the "osmotic sub-ensemble" approach, initially used as a molecular simulation scheme, 25 to experimental data. In simulation, one uses Eqs. 4 and 5 to calculate the stability of each host structure upon adsorption (and thus the transition pressures) from the simulated isotherms and the knowledge of the free energies of the empty host phases. Conversely, starting 
from an experimental stepped adsorption isotherm, one has some knowledge of the adsorption isotherms and the transition pressures. Thus, the free energies $F k_{\text {host }}$ can be determined from the experimental data if the full "rigid host" isotherms can be extrapolated from the stepped isotherm (see Fig. 5).

The method described above has the advantage of untangling the thermodynamics of the fluid adsorption and that of the structural deformation of the framework. It provides information on the intrinsic stability of the metastable structures of the soft porous crystal, e.g. their relative free energies, which are especially difficult to access either experimentally (by microcalorimetry) or by quantum chemistry calculations. One approximation is central to the method, however: the "rigid host" isotherms need to be extrapolated from a single stepped isotherms. While this may seem like a fairly big approximation, fitting parts of the stepped isotherms by Langmuir equations was shown to perform very well on a variety of \{adsorbate, host\} couples. This success owes to the fact that the adsorption of small gas molecules in common MOFs follows very smooth type I isotherms, which in turn are well described by equations such as Langmuir's. Moreover, in cases were a more complex functional form is necessary, more complex descriptions of the isotherms (such as the Langmuir-Freundlich equation) can be, and have been, used within this method. ${ }^{57}$

Moreover, because the mathematical equations of Langmuirtype adsorption in the osmotic ensemble are simple, their behaviour can be studied analytically. It was shown that, for such a bistable framework, the five key parameters that determine entirely the existence of adsorption-induced transitions are: the Henry constants, $K_{\mathrm{H}, 1}$ and $K_{\mathrm{H}, 2}$, the saturation uptakes, $N_{\max , 1}$ and $N_{\max , 2}$, and the free energy difference $\Delta F_{\text {host. }}$ Depending on these parameters, the taxonomy of guest-induced transitions includes three cases: no transition, one or two transitions. Gate-opening belongs to the second case, while the breathing materials (as the MIL-53 family) belong to the later category. Furthermore, the same material can belong to difference categories depending on the adsorption properties, which vary with the nature of the guest or the temperature of the system. For example, the existence or absence of breathing in MIL-53 (Al) for different short hydrocarbons (from methane to butane) was rationalized in terms of relative hydrocarbon-MIL affinities. The surprising logarithmic relationship between the breathing pressures and the adsorption enthalpies among this family, observed experimentally, ${ }^{105}$ could also be explained with this model. ${ }^{106}$

\subsection{Evolution with temperature}

As was noted above, while initial studies on guest-induced structure transformations of soft porous crystals typically focussed on structure resolution and energetic studies (e.g., using "zero Kelvin" quantum chemistry calculations), the full thermodynamic picture requires to study the evolution of the system under temperature changes. Few experimental studies include adsorption measurements over a wide temperature range, although some results were reported for gate opening. ${ }^{90,107,108}$ Indeed, most authors simply study the existence or absence of flexibility at room temperature (or liquid nitrogen temperature), even though the same guest could actually trigger structural transitions in different thermodynamic conditions. After the first studies showing the influence of temperature on gate opening pressures, and on the breathing of an amino-substituted MIL53,63 the first detailed study of the temperature-dependence of a breathing material was reported recently. ${ }^{109}$ This analysis of the behaviour of xenon adsorption in MIL-53 (Al) coupled experimental data from gravimetric adsorption with a theoretical model based on the osmotic ensemble, where the parameters describing the host framework and fluid adsorption were considered temperature-dependent. It demonstrated that xenon can only induce the breathing of MIL-53 (Al) in a limited range of temperature, between $\sim 200 \mathrm{~K}$ and $300 \mathrm{~K}$ (see Fig. 6). At lower temperature, the empty MIL-53 (Al) framework is in its narrowpore (np) form, as was previously demonstrated by neutron diffraction (although a large hysteresis was present in that study, preventing the assignment of a precise equilibrium temperature). ${ }^{54}$ The driving forces of this temperature-induced transition between large-pore (Ip) and $\mathbf{n p}$ forms are the following: the denser $\mathbf{n p}$ structure is more stable from a purely energetic point of view, while the Ip phase is entropically favoured. As a consequence, there is only one structural transition upon guest adsorption at low temperature, which corresponds to the entropydriven opening of the framework ( $\mathrm{np} \rightarrow \mathbf{I p}$ transition).

At temperatures higher than $300 \mathrm{~K}$, however, the situation is quite different. The stable state of the empty MIL-53 (AI) is the large-pore (Ip) structure, and because of the high temperature, this structure is much more stable than the np one. As a consequence, the difference in guest affinity between the two forms is not large enough to trigger the breathing, and the structure remains in the Ip form as pressure increases. These results, put together, form a phase diagram for the material upon xenon adsorption, as a function of temperature and vapour pressure, presented in Fig. 6. Because the thermodynamic considerations detailed above are very general, the overall shape of the phase diagram and its main features (re-entrancy, existence of two critical temperatures for the system) are expected to hold for other adsorbates in this breathing materials of the MIL-53 family. ${ }^{110,111}$ Thus, the distinction usually performed in the literature, between guest molecules that trigger the breathing and those who don't, only gives limited information on the overall picture. The more general question to be followed for such investigations should be: in what range of thermodynamic conditions does a given guest trigger structural transitions of the material?

\subsection{Understanding and predicting coadsorption behaviour}

As stated earlier, among the most exciting applications of soft porous crystals is their possible use in adsorption separation processes. In this particular field, predictive analytical methods proved crucial in separation science and have been widely used for rigid nanoporous solids, and the extension of such methods and concepts to host solids presenting a flexible framework is a challenge that experimental and theoretical groups are starting to address. In addition to the molecular simulation methods dealing with coadsorption in soft porous crystals (described in Section 2), some direct experimental studies of gas separation in these flexible materials have started to appear, using both breakthrough experiments $^{59,63,} 112$ and equilibrium coadsorption measurements. ${ }^{60}$ In order to help rationalize these experimental results which, especially in the case of breakthrough profiles, are not necessarily straightforward to interpret, the OFAST method (Osmotic Framework Adsorbed Solution Theory) was proposed, ${ }^{113,114}$ which couples the thermodynamic equations of the osmotic ensemble with the Ideal Adsorbed Solution Theory (IAST). The latter, a coadsorption prediction method introduced by Myers and Prausnitz in $1965^{67}$ widely used in the field of 
adsorption technology, was shown to be applicable to adsorption of small gas molecules inside the pores of metal-organic frameworks. ${ }^{115,116}$ Extended in the osmotic ensemble, it allows the prediction of coadsorption properties using pure-component adsorption data as the only input. It enables calculations such as total adsorbed quantities, adsorption selectivities, and of particular relevance to flexible systems: for a given mixture, do structural transitions occur and at what pressure? Fig. 7 gives an example of the prediction allowed for a binary mixture of $\mathrm{CO}_{2}$ and $\mathrm{CH}_{4}$ in the MIL-53 (Al) material at root temperature, from the experimental pure-component data.

\subsection{Out of equilibrium: a stress-based model}

Finally, we shall say here a few words here about the out-ofequilibrium states of soft porous crystals, their relevance to the understanding of experimental data and possible ways to account for them. It is a fact that an overwhelming majority of adsorptiondesorption stepped isotherms reported in literature for flexible metal-organic frameworks also present hysteresis loops. Compared to the fact that adsorption in otherwise similar rigid solids typical shows a reversible type I isotherm, it is reasonable to conclude that these hysteresis loops are signatures of the presence of out-of-equilibrium (or metastable) states for the host material upon adsorption and desorption. Indeed, while the free energy difference between host structures is necessarily small if the soft porous crystal exhibits multistability, there might be high free energy barriers between these different metastable structures. Moreover, it has been shown by X-ray diffraction that, in some materials undergoing breathing or gate opening, there are ranges of pressure for which two of the structures of the solid coexist in the same sample. This furthers hints at the presence of hysteretic effects, with the system not at thermodynamic equilibrium.

While few rationalizations of these out-of-equilibrium effects have so far been put forth, a recent study proposed a thermomechanical model for them, mixing elements of adsorption thermodynamics with an assumption about the mechanical nature of the structure transition. ${ }^{117}$ The model is based on the adsorption-induced stress in the nanoporous solid, and the assumption is that for each structure of the material, there is a given amount of stress that it can withhold. Once the adsorptioninduced stress is larger than this threshold, the framework expands or collapses into another structure, depending on the sign of the stress. This model was shown to properly account for the double-transition breathing of MIL-53 upon xenon adsorption at $200 \mathrm{~K}$, as depicted in Fig. 8. Relying on this description of the hysteretic adsorption-induced structure transitions, it was further hypothesized that if, for some reason, the stress threshold of the material is not unique, but can vary throughout the experimental sample, the structure transitions will happen in a heterogeneous way, and in a range of pressure, similarly to what is observed experimentally. The reason for the variation of stress threshold can be, for example, the existence of a distribution of crystallite sizes, with different mechanical properties for particles of different sizes.

\section{Outlook}

Seeing the large and ever increasing number of flexible metalorganic frameworks being reported and tested for applications in the field of fluid adsorption and separation, it is clear that concepts and methods have to be developed that can help rationalize the many different behaviours observed, and shed some light into some of the intringuing phenomena reported. Theoretical models and methods, both analytical and numerical, have only started to be developped to account for the rich phenomenology of these soft porous crystals. As such, many questions remain open and some avenues have only been explored very partially.

We want to provide here three examples of issues that have yet to be addressed even though, in our view of the field, answering them would enable physical chemists to learn a lot about the behaviour of these flexible materials. Firstly, on the topic of explicit molecular simulation, as described in section 2.3: can one design an algorithm working around the severe shortcomings of osmotic-ensemble simulations of bistable (or, more generally, multistable) materials under adsorption? Secondly, a more fundamental issue about these multistable materials: what are the mechanisms and factors behind the nonequilibrium properties of these structure transitions (gate opening and breathing)? They present wide hysteresis loops, and for some materials it was shown that multiple phases can coexist in a single experimental sample, but little is known so far about what determines the width of the hystereses and makes this phase coexistence possible. Thirdly, and finally, while thermodynamic models have been proposed and used to describe adsorption in multistable materials (as discussed in section 3), no generic model exists that describes the phenomenology of large amplitude adsorption-induced swelling in soft porous crystals. There, the continuous nature of the physicochemical transformation makes a simple two-state model inappropriate, so that other approaches will need to be developed.

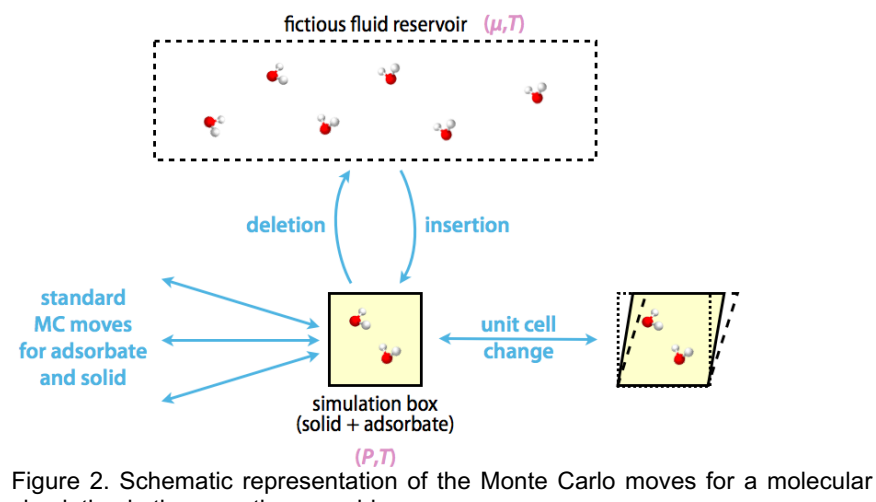
simulation in the osmotic ensemble. 


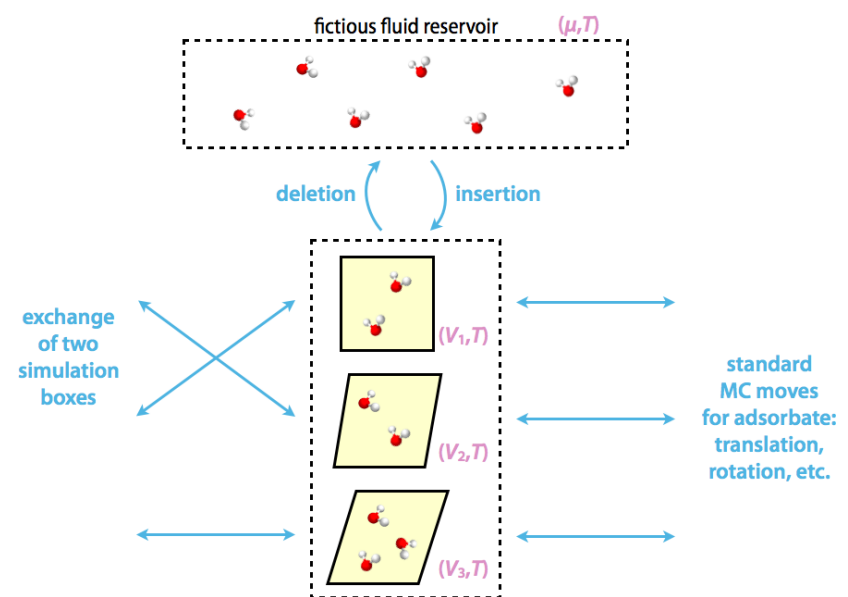

Figure 3. Schematic representation of the Monte Carlo moves in the restricted osmotic ensemble.
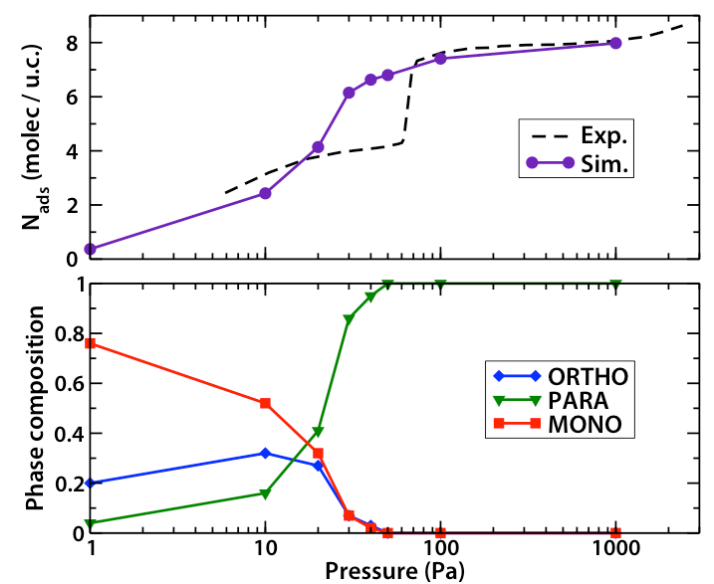

Figure 4. $\mathrm{C}_{2} \mathrm{Cl}_{4}$ adsorption isotherm calculated by molecular simulation in the osmotic sub-ensemble using the three silicalite-1 known structures (MONO, ORTHO and PARA) at $300 \mathrm{~K}$ (solid line) compared to experiments ${ }^{103}$ (dashed line). The probability of occurrence of each structure (MONO: red squares; ORTHO: blue diamonds; PARA: green triangles) is given in the lower panel.

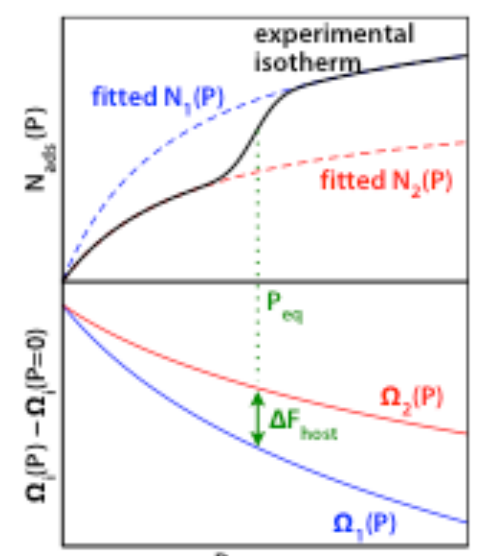

Pressure

Figure 5. Schematic representation of the determination of thermodynamic quantities, such as host free energy difference, from an experimental stepped adsorption isotherm. ${ }^{76}$ Reprinted with permission from ref. 114 .

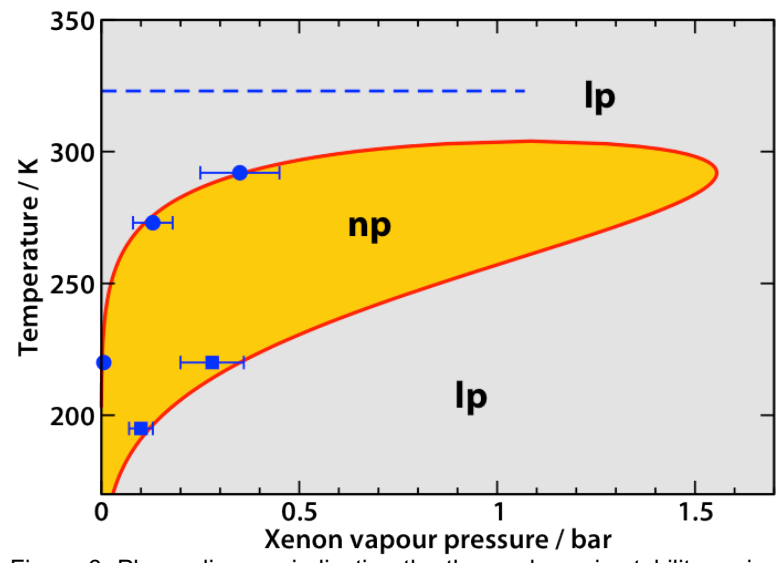

Figure 6. Phase diagram indicating the thermodynamic stability regions for the Ip and np structures of MIL-53 (Al), upon xenon adsorption, as a function of vapour pressure and temperature. The red symbols indicate experimental breathing pressures, while the blue line corresponds to the thermodynamic model. Reprinted with permission from ref. 109.

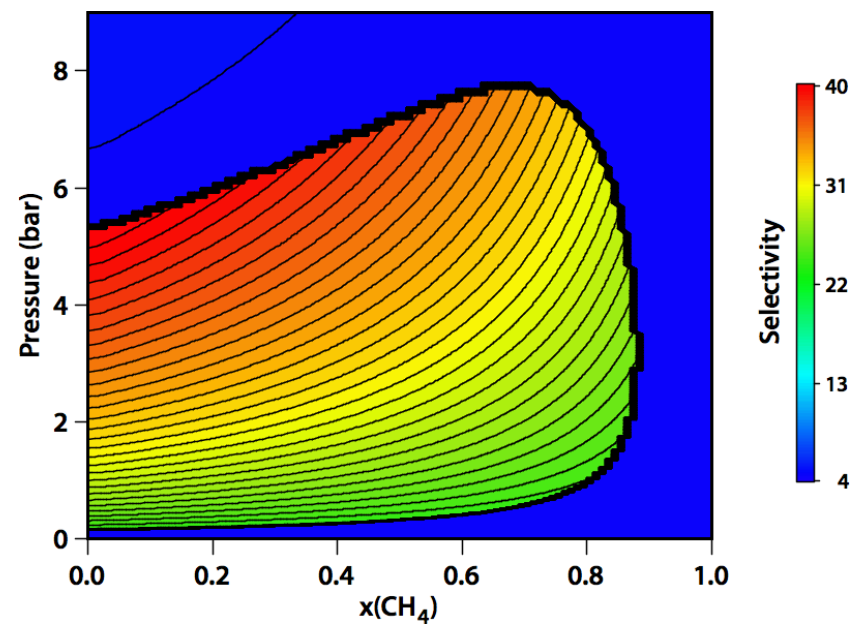

Figure 7: Diagram indicating the $\mathrm{CO}_{2}$ selectivity upon adsorption of a $\mathrm{CO}_{2} / \mathrm{CH}_{4}$ mixture in MIL-53 (Al) at $300 \mathrm{~K}$, as predicted by the OFAST method, as a function of mixture composition ( $x$ axis) and total gas pressure ( $y$ axis). The inner, high-selectivity island correspond to the np phase, delimited from the lower-selectivity Ip phase by a wide black line. Reprinted with permission from ref. 114.

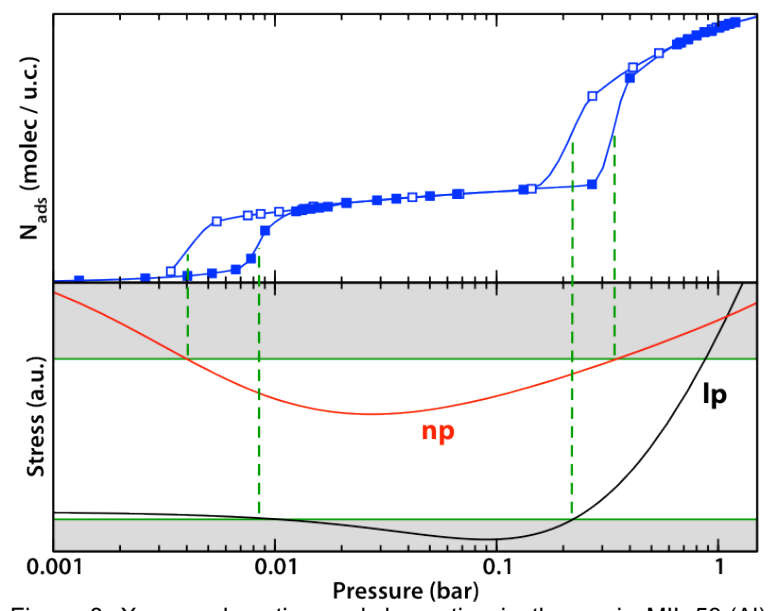

Figure 8: Xenon adsorption and desorption isotherms in MIL-53 (Al) at $220 \mathrm{~K}$ (upper panel) and adsorption-induced stress in each solid phase (lower panel). The stability region of both structures is indicated in white, and the unstable regions in gray. Vertical dashed lines indicate the structure transitions, which correspond to the stress in one phase crossing the stability limit. Reprinted with permission from ref. 117 


\section{Acknowledgements}

The authors are grateful to prof. Alex Neimark for a fruitful collaboration and many discussions. C. M.-D. thanks the EPSRC for an Advanced Research Fellowship.

Keywords: nanoporous materials $\cdot$ adsorption $\cdot$ statistical thermodynamics · soft porous crystals · osmotic ensemble

[1] S. Kitagawa, R. Kitaura, S. Noro, Angew. Chem. Int. Ed. 2004, 43, 2334 2375 .

[2] J. L. C. Rowsell, O. M. Yaghi, Microporous Mesoporous Mater. 2004, 73 3-14.

[3] G. Férey, Chem. Soc. Rev. 2008, 37, 191-214.

[4] Themed issue: metal organic frameworks, Chem. Soc. Rev. 2009, 38 , 1201

[5] G. Férey, C. Serre, Chem. Soc. Rev. 2009, 38, 1380-1399.

[6] M. Latroche, S. Surblé, C. Serre, C. Mellot-Draznieks, P. L. Llewellyn, J.H. Lee, J.-S. Chang, S. H. Jhung, G. Férey, Angew. Chem. Int. Ed. 2006, 45, 8227-8231.

[7] M. Eddaoudi, J. Kim, N. Rosi, D. Vodak, J. Wachter, M. O’Keeffe, O. M Yaghi, Science 2002, 295, 469-472.

[8] R. Banerjee, A. Phan, B. Wang, C. Knobler, H. Furukawa, M. O'Keeffe, O. M. Yaghi, Science 2008, 319, 939-943.

[9] J. R. Li, R. J. Kuppler, H.-C. Zhou, Chem. Soc. Rev. 2009, 38, $1477-$ 1504.

[10] L. J. Murray, M. Dinca, J. R. Long, Chem. Sov. Rev. 2009, 38, 1294 1314.

[11] S. S. Han, J. L. Mendoza-Cortés, W. A. Goddard III, Chem. Soc. Rev. 2009, 38, 1460-1476.

[12] L. Alaerts, C. E. A. Kirschhock, M. Maes, M. A. van der Veen, V. Finsy, A Depla, J. A. Martens, G. V. Baron, P. A. Jacobs, J. F. M. Denayer, D. E. De Vos, Angew. Chem. Int. Ed. 2007, 46, 4293-4297.

[13] D. Farrusseng, S. Aguado, C. Pinel, Angew. Chem. Int. Ed. 2009, 48, 7502-7513.

[14] P. Horcajada, C. Serre, M. Vallet-Regi, M. Sebban, F. Taulelle, G. Férey, Angew. Chem. Int. Ed., 2006, 45, 5974.

[15] Y. Lee, J. A. Hriljac, T. Vogt, J. B. Parise, M. J. Edmonson, P. A. Anderson, D. R. Corbin, T. Nagai, J. Am. Chem. Soc. 2001, 123,84188419 .

[16] Y. Lee, T. Vogt, J. A. Hriljac, J. B. Parise, G. Artioli, J. Am. Chem. Soc. 2002, 124, 5466-5475.

[17] J. B. Parise, E. Prince, Mater. Research Bull. 1983, 18, 841-852.

[18] W. Miller, C. W. Smith, D. S. Mackenzie, K. E. Evans, J. Mater. Sci. 2009 44, 5441-5451.

[19] L. A. Villaescusa, P. Lightfoot, S. J. Teat, R. E. Morris, J. Am. Chem. Soc 2001, 123, 5453-5459.

[20] M. P. Attfield, A. W. Sleight, Chem. Mater. 1998, 10, 2013-2019.

[21] F. Leroy, B. Rousseau, A. H. Fuchs, Phys. Chem. Chem. Phys. 2004, 6, 775.

[22] S. M. Auerbach, Int. Rev. Phys. Chem. 2000, 19 155-198.

[23] A. F. Combariza, G. Sastre, A. Corma, J. Phys. Chem. C 2009, 113, 11246-11253.

[24] F. Jousse, D. P. Vercauteren, S. M. Auerbach, J. Phys. Chem. B 2000, 104, 8768-8778.

[25] M. Jeffroy, A. H. Fuchs, A. Boutin, Chem. Commun. 2008, 3275-3277.

[26] R. Q. Snurr, A. T. Bell, D. N. Theodorou, J. Phys. Chem. 1993, 97, 13742.

[27] J.-R. Hill, J. A. Stuart, A. R. Minihan, E. Wimmer, C. J. Adams, Phys. Chem. Chem. Phys. 2000, 2, 4249-4254.

[28] J. Plévert, T. M. Gentz, A. Laine, H. Li, V. G. Young, O. M. Yaghi, M. O'Keefe, J. Am. Chem. Soc. 2001, 123, 12706-12707.

[29] A. Bieniok, W. H. Baur, J. Solid State Chem. 1991, 90, 173-177.
[30] D. R. Corbin, L. Abrams, G. A. Jones, M. M. Eddy, W. T. A. Harrison, G. D. Stucky, D. E. Cox, J. Am. Chem. Soc. 1990, 112, 4821-4830.

[31] D. Dubbeldam, K. S. Walton, D. E. Ellis, R. Q. Snurr, Angew. Chem. Int Ed. 2007, 46, 4496-4499.

[32] A. L. Goodwin, M. Calleja, M. J. Conterio, M. T. Dove, J. S. O. Evans, D. A. Keen, L. Peters, M. G. Tucker, Science 2008, 319, 794-797.

[33] D. Bradshaw, J. B. Claridge, E. J. Cussen, T. J. Prior, M. J. Rosseinsky, Acc. Chem. Res. 2005, 38, 273-282.

[34] A. J. Fletcher, K. M. Thomas, M. J. Rosseinsky, J. Solid State Chem. 2005, 178, 2491-2510.

[35] S. Kitagawa, K. Uemura, Chem. Soc. Rev. 2005, 34, 109-119.

[36] K. Uemura, R. Matsuda, S. Kitagawa, J. Solid State Chem. 2005, 178 2420-2429

[37] S. Horike, S. Shimomura, S. Kitagawa, Nature Chem. 2009, 1, 695-704.

[38] C. Mellot-Draznieks, C. Serre, S. Surblé, N. Audebrand, G. Férey, J. Am. Chem. Soc. 2005, 127, 16273-16278.

[39] C. Serre, C. Mellot-Draznieks, S. Surblé, N. Audebrand, Y. Filinchuk, G. Férey, Science 2007, 315, 1828

[40] D. I. Kolokolov, H. Jobic, A. G. Stepanov, V. Guillerm, T. Devic, C. Serre G. Férey, Angew. Chem. Int. Ed. 2010, 49, 4791-4794.

[41] C. Serre, F. Millange, C. Thouvenot, M. Nogues, G. Marsolier, D. Louër G. Férey, J. Am. Chem. Soc. 2002, 124, 13519-13526.

[42] F. Millange, C. Serre, G. Férey, Chem. Commun. 2002, 822.

[43] T. Loiseau, C. Serre, C. Huguenard, G. Fink, F. Taulelle, M. Henry, T. Bataille, G. Férey, Chem. Eur. J. 2004, 10, 1373-1382.

[44] R. Kitaura, K. Seki, G. Akiyama, S. Kitagawa, Angew. Chem. Int. Ed. 2003, 42, 428-431.

[45] J. Seo, R. Matsuda, H. Sakamoto, C. Bonneau, S. Kitagawa, J. Am. Chem. Soc. 2009, 131, 12792-12800.

[46] D. Li, K. Kaneko, Chem. Phys. Lett. 2001, 335, 50-56.

[47] D. Tanaka, K. Nakagawa, M. Higuchi, S. Horike, Y. Kubota, T. C. Kobayashi, M. Takata, S. Kitagawa, Angew. Chem. Int. Ed. 2008, 47, 3914-3918.

[48] X. C. Huang, Y. Y. Lin, J. P. Zhang and X. M. Chen, Angew. Chem. Int. Ed. 2006, 45, 1557

[49] Y. Liu, V. C. Kravtsov, R. Laren, M. Eddaoudi, Chem. Comm. 2006, 1488.

[50] K. S. Park, Z. Ni, A. P. Côté, J. Y. Choi, R. D. Huang, F. J. Uribe-Romo, H. K. Chae, M. O'Keeffe, O. M. Yaghi, Proc. Natl. Acad. Sci. U. S. A. 2006, 103, 10186.

[51] R. Banerjee, A. Phan, B. Wang, C. Knobler, H. Furukawa, M. O’Keeffe, O. M. Yaghi, Science 2008, 319, 939.

[52] G. H. Cui, J. R. Li, J. L. Tian, X. H. Buand S. R. Batten, Cryst. Growth Des. 2005 5, 1775.

[53] D. W. Lewis, A. R. Ruiz-Salvador, A. Gomez, L. M. Rodriguez-Albelo, F.X. Coudert, B. Slater, A. K. Cheetham, C. Mellot-Draznieks, CrystEngComm 2009, 11, 2272-2276.

[54] Y. Liu, J.-H. Her, A. Dailly, A.J. Ramirez-Cuesta, D.A. Neumann, C.M. Brown, J. Am. Chem. Soc. 2008, 130, 11813-11818.

[55] I. Beurroies, M. Boulhout, P. L. Llewellyn, B. Kuchta, G. Férey, C. Serre, R. Denoyel, Angew. Chem. Int. Ed. 2010, 49, 7526-7529.

[56] K. S. Murray, C. J. Kepert, Top. Curr. Chem. 2004, 233, 195-228.

[57] Z. Wang, S. M. Cohen, J. Am. Chem. Soc. 2009, 131, 16675-16677.

[58] A. U. Czaja, N. Trukhan, U. Müller, Chem. Soc. Rev. 2009, 38, 1284 1293

[59] V. Finsy, L. Ma, L. Alaerts, D. E. De Vos, G.V. Baron, J. F. M. Denayer, Microporous Mesoporous Mater. 2009, 120, 221-227.

[60] L. Hamon, P. L. Llewellyn, T. Devic, A. Ghoufi, G. Clet, V. Guillerm, G. D. Pirngruber, G. Maurin, C. Serre, G. Driver, W. van Beek, E. Jolimaître, A. Vimont, M. Daturi, G. Férey, J. Am. Chem. Soc. 2009, 131, 1749017499.

[61] D. S. Coombes, F. Cora, C. Mellot-Draznieks, R. G. Bell, J. Phys. Chem. C 2009, 113, 544-552.

[62] F. Salles, A. Ghoufi, G. Maurin, R. G. Bell, C. Mellot-Draznieks, G. Férey, Angew. Chem. Int. Ed. 2008, 47, 8487-8491.

[63] S. Couck, J. F. M. Denayer, G. V. Baron, T. Rémy, J. Gascon, F. Kapteijn, J. Am. Chem. Soc. 2009, 131, 6326-6327.

[64] A. Torrisi, C. Mellot-Draznieks, R. G. Bell, J. Chem. Phys. 2010, 131, 044705 .

[65] A. Torrisi, R. G. Bell, C. Mellot-Draznieks, Cryst. Growth Des. 2010, 10 , 2839-2841. 
[66] P. Horcajada, C. Serre, G. Maurin, N. A. Ramsahye, F. Balas, M. ValletRegi, M. Sebban, F. Taulelle, G. Férey, J. Am. Chem. Soc., 2008, 130, 6774 .

[67] A. L. Myers, J. M. Prausnitz, AlChE J. 1965,11,121-127.

[68] R.T. Yang, Gas separation by adsorption processes; Imperial College Press, London, 1997.

[69] S. Fritzsche, M. Wolfsberg, R. Haberlandt, P. Demontis, G. B. Suffritti, A Tilocca, Chem. Phys. Lett. 1998, 296, 253-258.

[70] P. Demontis, G. B. Suffritti, Chem. Rev. 1997, 97, 2845-2878.

[71] P. Santikary, S. Yashonath, J. Phys. Chem. 1994, 98, 9252-9259.

[72] S. Y. Bhide, S. Yashonath, J. Phys. Chem. A 2002, 106, 7130-7137.

[73] C. R. A. Catlow, C. M. Freeman, B. Vessal, S. M. Tomlinson, M. J. Leslie, Chem. Soc., Faraday Trans. 1991, 87, 1947.

[74] F.-X. Coudert, R. Vuilleumier, A. Boutin, Chem. Phys. Chem. 2006, 7, 2464-2467.

[75] D. Dubbeldam, R. Krishna, R. Q. Snurr, J. Phys. Chem. C 2009, 113, 19317-19327.

[76] F.-X. Coudert, M. Jeffroy, A. H. Fuchs, A. Boutin, C. Mellot-Draznieks, J. Am. Chem. Soc. 2008, 130, 14294-14302.

[77] M. Mehta, D. A. Kofke, Chem. Eng. Sci. 1994, 49, 2633-2645.

[78] T. Spyriouni, I. G. Economou, D. N. Theodorou, Phys. Rev. Lett. 1998, 80, 4466-4469.

[79] J. K. Brennan, W. G. Madden, Macromolecules 2002, 35, 2827-2834.

[80] B. J. Banaszak, R. Faller, J. J. de Pablo, J. Chem. Phys. 2004, 120, 11304-11315.

[81] R. Q. Snurr, A. T. Bell, D. N. Theodorou, J. Phys. Chem. 1994, 98, 5111-5119.

[82] J. Shen, P. A. Monson, Mol. Phys. 2002, 100, 2031-2039.

[83] F. Faure, B. Rousseau, V. Lachet, P. Ungerer, Fluid Phase Equilib. 2007, $261,168-175$.

[84] F. A. Escobedo, J. Chem. Phys. 1998, 108, 8761.

[85] B. Smit, J. I. Siepmann, J. Phys. Chem. 1994, 98, 8442.

[86] C. F. Mellot, A. K. Cheetham, S. Harms, S. Savitz, R. J. Gorte, A. L. Myers, Langmuir 1998, 14, 6728.

[87] V. Lachet, A. Boutin, B. Tavitian, A. H. Fuchs, J. Phys. Chem. B 1998 , $102,9224$.

[88] A. Di Lella, N. Desbiens, A. Boutin, I. Demachy, P. Ungerer, J.-P. Bellat A. H. Fuchs, Phys. Chem. Chem. Phys. 2006, 8, 5396.

[89] S. Paranthaman, F.-X. Coudert, A. H. Fuchs, Phys. Chem. Chem. Phys. 2010, 12, 8123-8129.

[90] K. L. Mulfort, O. K. Farha, C. D. Malliakas, M. G. Kanatzidis, J. T. Hupp, Chem. Eur. J. 2010, 16, 276-281.

[91] T. K. Maji, R. Matsuda, S. Kitagawa, Nature Mater. 2007, 6, 142-148.

[92] S. Watanabe, H. Sugiyama, H. Adachi, H. Tanaka, M. T. Miyahara, J. Chem. Phys. 2009, 130, 164707.

[93] J. A. Greathouse, T. L. Kinnibrugh, M. A. Allendorf, Ind. Eng. Chem. Res. 2009, 48, 3425-3431.
[94] V. A. Ermoshin, K. S. Smirnov, D. Bougeard, Chem. Phys. 1996, 202, 53-61.

[95] M. Tafipolsky, S. Amirjalayer, R. Schmid, J. Comput. Chem. 2007, 28, 1169-1176.

[96] Q. Xu, C. Zhong, J. Phys. Chem. C, 2010, 114, 5035-5042.

[97] Duane, A. D. Kennedy, B. J. Pendleton, D. Roweth, Phys. Lett. B 1987, 195, 216.

[98] B. Mehlig, D. W. Heermann, B. M. Forrest, Phys. Rev. B 1992, 45, 679685.

[99] R. Faller, J. J. de Pablo, J. Chem. Phys. 2002, 116, 55-59.

[100] A. Ghoufi, G. Maurin, J. Phys. Chem. C 2010, 114, 6496-6502.

[101] B. K. Peterson, K. E. Gubbins, Mol. Phys. 1987, 62, 215.

[102] J. Puibasset, R. J.-M. Pellenq, J. Chem. Phys. 2005, 122, 094704.

[103] N. Floquet, J. P. Coulomb, G. Weber, O. Bertrand, J. P. Bellat, J. Phys. Chem. B 2003, 107, 685.

[104] There are also a number of cases where stepped isotherms can be attributed to strong sorbate-sorbate interactions, leading upon adsorption to structural rearrangements of the adsorbed phase, similarly to what occurs for a number of \{zeolite, guest\} systems. The phenomenology of such systems has been extensively studied and is appropriately described within the grand canonical ensemble.

[105] P. L. Llewellyn, G. Maurin, T. Devic, S. Loera-Serna, N. Rosenbach, C. Serre, S. Bourrelly, P. Horcajada, Y. Filinchuk, G. Férey, J. Am. Chem. Soc. 2008, 130, 12808.

[106] F.-X. Coudert, C. Mellot-Draznieks, A. H. Fuchs, A. Boutin, J. Am. Chem. Soc. 2009, 131, 3442-3443.

[107] H.-S. Choi, M. P. Suh, Angew. Chem. Int. Ed. 2009, 48, 6865-6869.

[108] H. J. Park, M. P. Suh, Chem. Commun. 2010, 46, 610-612.

[109] A. Boutin, M.-A. Springuel-Huet, A. Nossov, A. Gédéon, T. Loiseau, C. Volkringer, G. Férey, F.-X. Coudert, Alain H. Fuchs, Angew. Chem. Int. Ed. 2009, 48, 8314-8317.

[110] A. Boutin, S. Couck, F.-X. Coudert, P. Serra-Crespo, J. Gascon, F. Kapteijn, A. H. Fuchs, J. F. M. Denayer, Micro. Meso. Mater. 2010, DOI: 10.1016/j.micromeso.2010.07.009

[111] A. Boutin, F.-X. Coudert, M.-A. Springuel-Huet, A. V. Neimark, G. Férey, A. H. Fuchs, DOI: 10.1021/jp108710h.

[112] K. Nakagawa, D. Tanaka, S. Horike, S. Shimomura, M. Higuchi, S. Kitagawa, Chem. Commun. 2010, 46, 4258-4260.

[113] F.-X. Coudert, C. Mellot-Draznieks, A. H. Fuchs, A. Boutin, J. Am. Chem. Soc. 2009, 131, 11329-11331.

[114] F.-X. Coudert, Phys. Chem. Chem. Phys. 2010, 12, 10904-10913.

[115] Y.-S. Bae, K. L. Mulfort, H. Frost, P. Ryan, S. Punnathanam, L. J. Broadbelt, J. T. Hupp, R. Q. Snurr, Langmuir 2008, 24, 8592-8598.

[116] Q. Yang, C. Xue, C. Zhong, J.-F. Chen, AIChE J. 2007, 53, 2832-2840.

[117] A. V. Neimark, F.-X. Coudert, A. Boutin, A. H. Fuchs, J. Phys. Chem. Lett. 2010, 1, 445-449. 